\title{
Power Cord Device
}

National Cancer Institute

\section{Source}

National Cancer Institute. Power Cord Device. NCI Thesaurus. Code C49892.

A flexible cable designed to connect an electric device to a power source. 